\title{
Tumores benignos que producen fracturas en niños
}

\author{
Cortés-Cerda R,* Mora-Ríos FG, ${ }^{* *}$ Insunza-Ramírez A, ${ }^{* * *}$ Mejía-Rohenes LC,**** Ruiz-Alva SK,* \\ Pérez García CK*****
}

Hospital Regional Ignacio Zaragoza, ISSSTE

RESUMEN. Introducción: Se define fractura patológica a la que se produce a través de un hueso anormal. Cada año se diagnostican aproximadamente 20,000 neoplasias benignas del sistema musculoesquelético. A menudo, el dolor de la fractura es el primer síntoma de un proceso patológico en el hueso. El sitio, la edad y la apariencia radiográfica crean un diagnóstico diferencial para las fracturas patológicas que sigue siendo amplio. El examen clínico evalúa la condición de la piel, palpar cualquier masa de tejido y determinar si hay signos inflamatorios locales como eritema, calor o edema. La toma de biopsia es muy recomendable para confirmar el diagnóstico de una fractura patológica. Objetivo: Determinar qué tumores óseos benignos y qué lesiones seudotumorales producen fracturas en huesos de niños con mayor frecuencia en nuestro hospital. Material y métodos: Estudio retrospectivo transversal, se revisaron expedientes de pacientes con diagnóstico de fractura en terreno patológico, atendidos en el período de Marzo de 2013 a Marzo de 2017. Resultados: Los tumores benignos que ocasionaron fracturas en terreno previamente dañado fueron: quiste óseo aneurismático 13, encondroma cinco, osteoma osteoide tres, tumor de células gigantes dos. Conclusión: En nuestra institución, los quistes óseos aneurismáticos fueron los tumores benignos que con mayor frecuencia producen fracturas patológicas en niños, con predominio en el sexo masculino.

Palabras clave: Fractura, patológica, tumor, óseo, benigno, pediátrica.
ABSTRACT. Introduction: A pathological fracture is defined as that which occurs through an abnormal bone. Approximately 20,000 benign neoplasms of the musculoskeletal system are diagnosed each year. Often the pain of the fracture is the first symptom of a pathological process in the bone. The site, age and radiographic appearance create a differential diagnosis for pathological fractures that remains broad. The clinical examination evaluates the condition of the skin, palpating any tissue mass and determining if there are local inflammatory signs such as erythema, heat or edema. The biopsy is highly recommended to confirm the diagnosis of a pathological fracture. Objective: To determine which benign bone tumors and pseudotumoral lesions produce fractures in children's bones more frequently in our institution. Material and methods: Cross-sectional retrospective study, review of records of patients with diagnosis of pathological fracture, attended in the period from March 2013 to March 2017, were reviewed. Results: The benign tumors that caused fractures in previously damaged areas were: aneurysmal bone cyst 13, enchondroma 5, osteoid osteoma 3, giant cell tumor 2. Conclusion: At our institution, aneurysmal bone cysts were the benign tumors that most frequently produce pathological fractures in children, with predominance in males.

Key words: Fracture, pathological, tumor, bone, benign, pediatric.

\footnotetext{
* Médico Residente de cuarto año de Ortopedia y Traumatología, Universidad La Salle. Hospital Regional Ignacio Zaragoza, ISSSTE Ciudad de México, México.

** Médico adscrito al Módulo Pediátrico. Hospital Regional «Ignacio Zaragoza», ISSSTE Ciudad de México, México.

*** Médico Ortopedista Pediatra, Hospital Ángeles Pedregal.

**** Jefe de Servicio y Profesor Titular del Curso de Ortopedia, Hospital Regional «Ignacio Zaragoza», ISSSTE Ciudad de México, México.

***** Médico Residente de tercer año de Ortopedia y Traumatología, Universidad La Salle. Hospital Regional «Ignacio Zaragoza», ISSSTE Ciudad de México, México.
}

Dirección para correspondencia:

Dr. Ricardo Cortés Cerda

Av. Gral. Ignacio Zaragoza Núm. 1711, CP 09220, Col. Unidad Habitacional Ejercito Constitucionalista, Del. Iztapalapa, Ciudad de México, México.

Tel: 57165200, ext. 16725

E-mail: oslomza@hotmail.com

Este artículo puede ser consultado en versión completa en http://www.medigraphic.com/actaortopedica 


\section{Introducción}

Se define como una fractura patológica a la que se produce a través de un hueso anormal. ${ }^{1}$ Resultado de una fuerza aparentemente normal aplicada a un hueso que carece de sus propiedades biomecánicas y viscoelásticas habituales. ${ }^{2}$ Las fracturas patológicas pueden ser consecuencia de procesos intrínsecos o extrínsecos. Además, pueden ser consecuencia de procesos localizados o generalizados. ${ }^{1}$

EL hueso patológico falla de dos modos diferentes. En el primero, la energía requerida para producir una fractura patológica puede ser tan pequeña como la carga repetida del soporte de pesos. El segundo modo de fractura proviene de la aplicación de fuerzas y la fractura se determina con base en su relación con el hueso defectuoso. ${ }^{2}$

A menudo el dolor de la fractura es el primer síntoma de un proceso patológico en el hueso. ${ }^{3}$ Los médicos deben ser conscientes de que las fracturas pueden presentarse con dolor, incapacidad para soportar las cargas y frecuentemente tienen desplazamiento. ${ }^{2}$ Es importante prestar atención al mecanismo de lesión, ya que, si éste es inadecuado para el patrón de fractura, podemos sospechar de una lesión ósea patológica.

La técnica de imagen inicial de elección para la valoración de la patología ósea es la radiografía simple; la cual nos va a permitir detectar la mayoría de lesiones y establecer un diagnóstico bastante preciso. ${ }^{4}$ La mayoría de los tumores y procesos seudotumorales son identificables por su aspecto radiográfico. ${ }^{1}$ También puede ser de utilidad la localización de la lesión. La tomografía computarizada (TC) se emplea sobre todo para los casos en los que se tomará biopsia. La resonancia magnética (RM) se emplea para caracterizar la lesión detectada mediante radiología, determinar su extensión y la afectación de partes blandas. ${ }^{4}$

El sitio, la edad y la apariencia radiográfica crean un diagnóstico diferencial para las fracturas patológicas que siguen siendo amplio. Como resultado, cada caso debe enfocarse desde una perspectiva que abarque la edad, los síntomas, la apariencia de la imagen y la comprensión de la biología ósea. ${ }^{3}$

Los estudios de laboratorio por sí solos son inespecífi$\cos ^{5}$ Estos deben complementarse con estudios de imagenología y la biopsia para confirmar el diagnóstico sospechado. ${ }^{3}$

Quiste óseo unicameral (QOU). Considerada la causa más común de fracturas patológicas. ${ }^{6,7}$ Son lesiones radiotransparentes, expansivas, quísticas y rellenas de líquido, encontradas con mayor frecuencia en las metáfisis de los huesos largos. Húmero proximal y fémur proximal son los dos sitios más comunes para fracturas patológicas por QOU. ${ }^{6}$ Cerca de 75\% de los pacientes que sufren QOU se presentan con fracturas patológicas. La relación hombre mujer es de 2 a 1. Habitualmente los quistes se describen como activos si están adyacentes a la fisis y latentes si se sitúan a más de $0.5 \mathrm{~cm}$ de la fisis. Los pacientes con fracturas patológicas presentan dolor, de mínimo a moderado, en la extremidad después de un traumatismo menor. Las fracturas patológicas a través de QOU consolidan invariablemente con la simple inmovilización pasadas seis semanas, pero generalmente el QOU persiste, presentando a menudo una nueva fractura. De manera general, la infiltración de metilprednisolona tiene una tasa favorable de éxito, con una respuesta parcial en 50 a $80 \%$ de los pacientes. ${ }^{8}$ La intervención quirúrgica está indicada para pacientes seleccionados. A pesar de que los resultados funcionales con legrado abierto e injerto son perfectos, la descompresión intramedular con clavos elásticos conduce a una mayor velocidad de curación radiográfica. ${ }^{8,9}$

Quiste óseo aneurismático (QOA). Son lesiones osteolíticas expansivas, excéntricas o centrales, que generalmente se presentan en los extremos metafisarios de los huesos largos (65\%) o en los elementos posteriores de la columna vertebral durante la adolescencia. Cincuenta por ciento se detectan en pacientes con edades entre 10 y 20 años. Las lesiones no son realmente quísticas sino más bien se trata de colecciones seudoesponjosas de tejido fibroso interconectado y espacios rellenos de sangre. Es frecuente la presencia de septos dando lugar al aspecto de panal de abejas. Entre 11 y 35\% de los pacientes con QOA de los huesos largos presentan fracturas patológicas. No es adecuado el tratamiento conservador con inmovilización. La biopsia dirigida del área de mayor grosor (identificada por RM) es obligatoria antes de cualquier tratamiento. ${ }^{7}$ Es fundamental para el éxito del tratamiento la obtención de una exposición adecuada con una gran ventana cortical por donde realizar un legrado extenso y exhaustivo. En general, el tratamiento combinado mecánico y biológico con curetaje, clavo intramedular estable elástico, injerto óseo (artificial) como tratamiento de primera, segunda o tercera línea, alcanzará la resolución completa o casi completa en más de la mitad de los casos, ${ }^{10}$ por lo que debe utilizarse como tratamiento de primera línea y el uso de placa dejarse como una segunda opción. ${ }^{9}$

Osteocondroma. Son uno de los tumores óseos más frecuentes en los niños, incluyen lesiones solitarias y múltiples, ${ }^{11}$ estando la sintomatológica generalmente relacionada con la presencia de masas dolorosas que irritan partes blandas circundantes. Estas lesiones son normalmente pediculadas, pero pueden ser sésiles. ${ }^{5}$ Aunque son raras, pueden presentarse fracturas a través de la base o el tallo de un osteocondroma pediculado. ${ }^{11} \mathrm{El}$ tratamiento conservador suele ser suficiente. Las fracturas pueden solamente observarse, reservando la resección para aquellos casos con sintomatología persistente después de la consolidación.

Osteoma osteoide. El osteoma osteoide es un tumor óseo benigno de adultos jóvenes, que se ubica preferentemente en la cortical de los huesos largos de las extremidades inferiores. ${ }^{11}$ Produce una intensa reacción ósea y tiene un característico patrón de dolor. No tiene potencial de crecimiento y su tamaño rara vez supera $1.5 \mathrm{~cm}$, pese a que la esclerosis que lo rodea le da un aspecto mayor. Son relativamente comunes, constituyendo alrededor de $10 \%$ de los tumores óseos. Su manifestación clínica típica es el dolor nocturno. ${ }^{11}$ El tratamiento tradicional consiste en la resección abierta, 
en bloque, cuyas mayores dificultades son la localización del nido y la desproporción del abordaje quirúrgico respecto al tamaño de la lesión.

Encondroma. Es una lesión del cartílago hialino maduro, benigna y asintomática, que se desarrolla cerca de la placa de crecimiento, ${ }^{7}$ es el tumor cartilaginoso de hueso que se da, más a menudo, en adolescentes o adultos jóvenes; normalmente afecta a huesos tubulares pequeños de manos o pies (40-65\%). Es el tumor primario más común encontrado en las manos. El encondroma normalmente es asintomático, a menos que haya fractura patológica. ${ }^{5} \mathrm{Y}$ se presenta como un hallazgo incidental radiográfico. En la mayoría de los casos de fractura patológica, la fractura consolida con tratamiento cerrado. Después de la curación de la fractura, se requiere curetaje e injerto óseo, ya que la resolución espontánea del encondroma después de la curación de la fractura no es probable que ocurra.

Objetivo. Determinar qué tumores óseos benignos y qué lesiones seudotumorales producen fracturas en huesos de niños con mayor frecuencia en nuestra institución.

\section{Material y métodos}

Se realizó un estudio retrospectivo transversal, que consistió en revisar expedientes de pacientes con diagnóstico de fractura en terreno previamente dañado, con reporte histopatológico de tumor óseo benigno o lesión seudotumoral, con edad comprendida entre 0 a menores de18 años en el período comprendido de Marzo de 2013 a Marzo de 2017. Se contó con consentimiento autorizado por parte de por lo menos uno de los padres. No se contó con ningún tipo de apoyo económico en este estudio.

\section{Resultados}

Nuestro universo de estudio consistió en 24 pacientes; 13 hombres, 11 mujeres. Los tumores benignos que ocasionaron fracturas en terreno previamente dañado fueron: quiste óseo aneurismático 13 (Figura 1), encondroma seis, osteoma osteoide tres, tumor de células gigantes dos.

\section{Discusión}

En la bibliografía médica el tumor óseo benigno que con mayor frecuencia se asocia a fracturas patológicas en niños es el quiste óseo unicameral; sin embargo, en nuestro estudio encontramos que el tumor que con mayor frecuencia produjo fracturas en terreno patológico fue el quiste óseo aneurismático. En nuestro estudio también encontramos similitud respecto a que el género masculino presentó el mayor número de casos de fractura en terreno patológico asociada con tumores benignos.

Para el tratamiento no quirúrgico, la edad del paciente y la proximidad de la fractura con la fisis son consideraciones importantes para el manejo. Los huesos que soportan carga son tratados de manera diferente que los que no lo hacen.

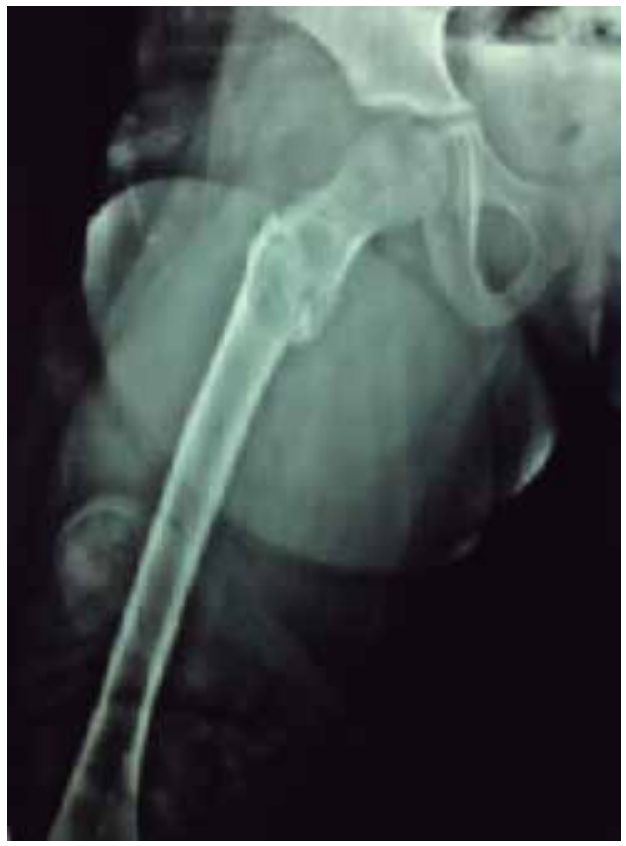

Figura 1: Radiografía anteroposterior, se observa quiste óseo aneurismático metáfisis proximal de fémur.

El tratamiento no quirúrgico está indicado para fracturas de extremidades superiores que pueden tratarse con éxito sin deformidad angular. Las fracturas de las extremidades inferiores, especialmente después de que se haya producido una deformidad, se tratan mejor con una fijación interna y con frecuencia requieren osteotomías. El objetivo final en el tratamiento es mantener la movilidad, la cual a menudo se logra al mantener la longitud y prevenir la deformidad.

El curetaje simple combinado con injerto óseo es el procedimiento quirúrgico más realizado, ${ }^{8}$ frecuentemente utilizado en tumores óseos benignos con verdadero potencial de crecimiento. Las opciones de tratamiento dependen de establecer un diagnóstico e implican la erradicación del tumor mediante resección intralesional, seguida de reconstrucción esquelética. ${ }^{12}$ La reconstrucción esquelética generalmente implica injerto óseo (autoinjerto o aloinjerto) con o sin la fijación interna con un implante metálico. El uso de sulfato cálcico, aloinjertos con o sin matriz ósea desmineralizada o los injertos óseos autógenos o la médula ósea dan como resultado una cicatrización exitosa en los sitios de fracturas patológicas después del curetaje en aproximadamente $50 \%$ de los casos.

Se debe realizar un protocolo de estudio tumoral completo a estos pacientes para tener una seguridad en su manejo, de modo que se pueda maximizar la curación ósea y obtener el mejor pronóstico posible, en virtud de que estos tumores pueden llegar a ocasionar temor en los padres, sobre todo los localizados en el área de la rodilla.

\section{Conclusión}

En nuestra institución, los quistes óseos aneurismáticos fueron los tumores benignos que con mayor frecuencia pro- 
ducen fracturas patológicas en los niños, con predominio en el sexo masculino.

Bibliografía

1. Beaty JM, Kasser JR. Fracturas patológicas asociadas a tumores y trastornos específicos del sistema músculo-esquelético. En: Beaty JM, Kasser JR. Rockwood \& Wilkin's. Fracturas en el niño. Madrid: Marbán; 2003.

2. Catterall A. Fracturas patológicas. En: De Pablos J, GonzálezHerranz P. Fracturas infantiles: conceptos y principios. Global HELP Organization; 2010.

3. Springfield SD, Gebhardt CM. Bone and soft tissue tumors. In: Morrissy-Raymond T, Weinstein-Stuart L, editors. Lovell \& Winter's Pediatric Orthopaedics. 6th ed. Baltimore, MD: Lippincott Williams \& Wilkins; 2006.

4. Rodríguez GA. Valoración radiológica de las imágenes líticas óseas. Pediatr Integral. 2012; 16(7): 565-73.

5. Tachdjian MO. Ortopedia pediátrica. Tumores de hueso. México: Interamericana; 1976.

6. Rapp M, Grauel F, Wessel LM, Illing P, Kaiser MM. Treatment outcome in 60 children with pathological fractures of the humerus caused by juvenile or aneurysmal bone cysts. Acta Orthop Belg. 2016; 82(4): 723-9.

7. Canavese F, Samba A, Rousset M. Pathological fractures in children: diagnosis and treatment options. Orthop Traumatol Surg Res. 2016; 102(1 Suppl): S149-59.

8. Guida P, Ragozzino R, Sorrentino B, Casaburi A, D’Amato RD, Federico G, et al. Three-in-One minimally invasive approach to surgical treatment of pediatric pathological fractures with wide bone loss through bone cysts: ESIN, curettage and packing with injectable HA bone substitute. A retrospective series of 116 cases. Injury. 2016; 47(6): 1222-8.

9. Yang $X$, Tang $X$, Jiang $X$, Liu L. A comparative study on two fixation methods for benign long bone pathological fractures in children. Zhongguo Xiu Fu Chong Jian Wai Ke Za Zhi. 2015; 29(6): 712-6.

10. Erol B, Onay T, Topkar OM, Tokyay A, Aydemir AN, Okay E. A comparative study for the treatment of simple bone cysts of the humerus: open curettage and bone grafting either without instrumentation or with intramedullary nailing. J Pediatr Orthop B. 2017; 26(1): 5-13.

11. Staheli LT. Ortopedia pediátrica. Tumores. Madrid: Marbán; 2003.

12. Ömeroğlu H. Basic principles of fracture treatment in children. Eklem Hastalik Cerrahisi. 2018; 29(1): 52-7. 